\title{
DECISION-MAKING IN CONDITIONS OF DILEMMA: RISKS AND MIXED INFORMATION UNCERTAINTY
}

\author{
Sultan Ramazanov ${ }^{1}$, Ludmila Stemplewska ${ }^{2}$ \\ ${ }^{1}$ Kyiv National Economic University named after Vadim Hetman, Kyiv, Ukraine \\ ${ }^{2}$ Vistula University, Vistula Academy of Finance and Business in Warsaw, Poland \\ e-mails: ${ }^{1}$ sramazanov@i.ua, $\underline{{ }^{2} \text {-stemplewska@wp.pl }}$
}

Received: 01 March 2020; Accepted: 24 May 2020; Published: 25 August 2020

\begin{abstract}
In modern conditions of crises and instability of the functioning and development of socio-economic systems, an important problem of providing management tools and making effective decisions is the development of models, methods and information technologies for optimization and decision-making in a situation of risk and in a mixed information environment. Moreover, the widespread introduction of optimization methods, decision making and optimal control was facilitated by the fact that applied optimization problems in most cases are reduced to standard problems solved, and the growth of the power of updated computer tools contributes to the expansion of the spheres of successful application of decision optimization methods in solving complex and diverse economic problems.

The paper proposes models of risk functions related to the decision-making task for harmonizing and optimizing risks and security of a complex system in a mixed information environment, and also proposes a model of penalties for damage to ensure the safety of functioning of complex systems. The work is a continuation of some of the authors' research in the field of modeling, forecasting and managing complex socio-ecological and economic systems to ensure safe, sustainable, sustainable and harmonious development in the face of modern risks and crises.
\end{abstract}

Key words: dilemma, risks, risk function, posterior risk, decision making, decision rule, Bayesian decision, minimax decision, guaranteed decision, information environment, penalty model.

JEL classification: C02; C11; C61; C65

Citation:

Ramazanov, S., Stemplewska, L. (2020). Decision-making in conditions of dilemma: risks and mixed information uncertainty. Access journal, ACCESS Press, 1(2): 112-121, https://doi.org/10.46656/access.2020.1.2(3)

\section{INTRODUCTION}

In the current environment of crises and unstable functioning and development of social and economic systems, an important problem related to provision of tools for management and efficient decision-making is development of the models, methods and information technologies of optimization and decision-making in the conditions of risks, danger, and mixed information environment.

At the same time, a wide implementation of the methods of optimization and optimal management was facilitated by the fact that the majority of applied optimization tasks imply solution of typical tasks, and the increase of the capacity of the updatable computing facilities helps to widen the spheres of successful 
application of the methods of optimization of decisions for resolving complex and diverse economic tasks (Ramazanow \& Stemplewska, 2014; Ramazanov et al, 2012; Ramazanov, 2009; Ramazanov, 2015).

\section{Task identification. Formulation of the risk function.}

The task of decision-making (DM) is exercised in the course of observation of a random process $Y(t)$, which is taking place either in a discrete or in a continuous way. If $y \in Y$ - is the space where various realizations of the $Y(t)$ random process occur, and $\theta$ - is some parameter (a vector in general) that belongs to the set range $\Omega$, which means that $\theta \in \Omega$ is the environment (the parametric space).

It is assumed that distribution of probability of the observed process $Y(t)$ depends on the parameter $\theta$, the value of which is unknown to the observer.

If a finite sequence of random variables is observed $\left\{y\left(t_{i}\right), i=\overline{1, n}\right\}$ - being the discrete realization of the process $Y(t)$, then it can be completely described with the help of $\mathrm{n}$ - dimensional probability distribution function (PDF), which depends on $\theta$, and we mark this function at this value of $\theta$ through $F(y / \theta)$. Here, $y_{1}^{n}$ is the dimensional vector, which means $y_{1}^{n}=\left(y_{1}, \ldots, y_{n}\right)$, where $y_{i}=y\left(t_{i}\right), i=\overline{1, n}$.

Note that the parameter $\theta$ may acquire both discrete values (e.g., 0 or 1 ) and a continuous set of values.

Here, the observed process $Y(t)$ is a kind of mixture of a useful component (information) with obstacles (mistakes), i.e $y(t)=H(x, v)$, where $x \equiv x(t)$, in this case, is the vector of the status of the studied system (process) where as $v \equiv v(t)$ is the vector of random obstacles (mistakes) during observations or dimensions of the experiment.

For instance, this can be a model of the following pattern:

$$
y(t)=\xi(t) x(t)+\zeta(t)
$$

i.e the multiplicatively additive mixture of the watch equation (Ramazanov, 2012).

It should be remembered that

$$
F(Y / \theta)=F\left(y_{1}, \ldots, y_{n} / \theta ; t_{1}, \ldots, t_{n}\right) \equiv P_{r}\left(Y_{1}<y_{1}, \ldots, Y_{n}<y_{n} / \theta\right), \quad \mathrm{y}_{i}=y\left(t_{i}\right) .
$$

Let us use $x^{*}$ to define an element of the set $X^{*} \subseteq X$ - being the array of all solutions that can be assigned with regard to the parameter $x \equiv \theta$ based on the results of observation of $Y(t)$ and use $\delta$ - to denote the decision function (DF) or the decision rule (DR), which belongs to the class of decision functions 
$\Delta$ and which reflects the array $Y$ in $X^{*}$, which means that in accordance with this decision rule of the each possible relation of $y \in Y$ determines a certain solution of $x^{*}=\delta(t), x^{*} \in X^{*} \subseteq X$ - the space of the system states.

Therefore, based on specific decisions, mistakes are possible. The "loss" inflicted on the observer - a person who decides (PD) in the end can be described by some function $\rho\left(x^{*}, x\right)$ selected on the basis of heuristic reasoning. This function is called the penalty function (PF) or the loss function (LF), and it determines the size of the losses incurred as a result of $x^{*}$ decision-making (DM) provided that the true value of the parameter is equal to $x$.

LF (PF) can be used to compare the decision rules and to select the most suitable of them. Since the solution of $x^{*}=\delta(t) \equiv \delta(y(t))$ depends on the realization of a random process $y$, the $\rho(x, \delta(y))$ LF has a random nature, and therefore it will be natural to select the DR on the basis of comparison of statistical (probability) characteristics of LF. In the DM theory, the mathematic expectation of the LF is usually used (although other characteristics may be taken into consideration as well).

The mathematic expectation of the LF when the value of $\mathrm{x}$ is known can be shows as ((Ramazanov et al, 2009; Ramazanov, 2015):

$$
r\left(x, x^{*}\right)=M_{Y}[\rho(x, \delta(y))]
$$

And called the risk function (RF). Sometimes (1) is called a conditional risk (CR). RF depends on the adopted decision rule (DR) $\delta$ and on the distribution of probability $F(y / x)$ :

$$
r\left(x, x^{*}\right)=\int_{Y} \rho(x, \delta(y)) d F(y / x)
$$

When a sequence of uninterrupted random variables is observed $\left\{y_{i}\right\}$, there is the probability density $f(y / x)$, where the RF can be described as follows:

$$
r\left(x, x^{*}\right)=\int_{Y} \rho(x, \delta(y)) f(y / x) d y
$$

It is said that the DR $\delta_{1}$ is uniformly better than $\delta_{2}$, provided the following inequalities are true: $r\left(x, \delta_{1}\right) \leq r\left(x, \delta_{2}\right) \forall x \in \Omega \subseteq X, r\left(x, \delta_{1}\right)<r\left(x, \delta_{2}\right)$, at least for one $\mathrm{x}$.

The DR $\delta^{*}$ is called acceptable if there is no other DR $\delta$ in the $\Delta$, which would be uniformly better than $\delta^{*}$. The DR $\tilde{\Delta}$ class is called complete if in $\forall \delta \notin \widetilde{\Delta}$ the DR $\delta^{*}$ can be found, which is uniformly 
better than $\delta$. The complete class $\tilde{\Delta}$ is called minimal if it does not contain any complete subclass of its own. If there is such complete class, then it coincides with the class of all acceptable DR.

Note that if the class $\tilde{\Delta}$ DR is complete, the selection of the most suitable decision function (DF), obviously, would be sufficient only within this class disregarding the DF $\delta \notin \widetilde{\Delta}$. Therefore, identification of complete classes is an important task of the DM theory.

\section{Optimization of decisions in the conditions of risk and dangers}

\subsection{Bayesian decision.}

It would be natural to assume that the most acceptable DR is the one that minimizes RF (1) for all values of $X$. However, this rule exists only in individual cases. Typically, the DF minimizing (1) depends on $X$, and for various values of $x$ it will be different; at the same time, it is not clear, which DF should be considered the best.

The aforementioned correlation can be excluded if one uses, for instance, the Bayesian approach to the problem of decision selection. The nature of this approach is the following.

It is expected that, first, the parameter $x$ is a random variable, the distribution of probability of which $F_{0}(x)$ exists, and second, the distribution of $F_{0}(x)$ (i.e., a priori distribution) is known to the PD (the observer).

Then, the average risk (AR) can be determined by taking the repeat mathematical expectation of the RF (1), treating the mathematical expectation of the RF as conditional (regarding $X$ ):

$$
R\left(F_{0}, \delta\right)=M\{M[\rho(x, \delta(y)) / x]\}=\int_{\Omega} r(x, \delta) d F_{0}(x) .
$$

Therefore, the $\operatorname{AR} R\left(F_{0}, \delta\right)$ is the complete mathematical expectation of the RF, that is

$$
R\left(F_{0}, \delta\right)=M[\rho(x, \delta(y))]
$$

where it depends on the a priori distribution of the variable $x$ and on the assumed DF.

If $x$ is a continuous random variable, and $\rho_{0}(x)$ - is the density of probability (a priori density). This means that the AR according to (3) and (2) can be written as:

$$
R\left(\rho_{0}, \delta\right)=\int_{\Omega} r(x, \delta) \rho_{0}(x) d x=\int_{\Omega} \int_{Y} \rho(x, \delta(y)) \rho(y / x) \rho_{0}(x) d y d x .
$$

The DF minimizing the $\mathrm{AR}$, i.e. the $\mathrm{DF} \delta^{*}$, for which $R\left(F_{0}, \delta^{*}\right) \leq R\left(F_{0}, \delta\right)$ with all values of $\delta \in \Delta$, is called the Bayes solution with regard to the a priori distribution $F_{0}(x)$.

The value of $R\left(F_{0}, \delta^{*}\right)$ is called the Bayes risk (BR) for $F_{0}(x)$. 
Therefore, the Bayes solution is the best or the optimal solution if the minimum AR is assumed as the optimum criterion - the Bayes criterion:

$$
R\left(F_{0}, \delta^{*}\right)=\inf _{\delta \in \Delta} R\left(F_{0}, \delta\right) .
$$

Here $\delta^{*}=\operatorname{Arg} \inf _{\delta} R\left(F_{0}, \delta\right)$.

Given the known Bayes' formula (Sosulin, 1978; Volodin, 2010), formula (5) can be rewritten as follows

$$
R\left(\rho_{0}, \delta\right)=\int_{Y} \widetilde{R}(y, \delta) \rho(y) d y
$$

where

$$
\tilde{R}(y, \delta)=\int_{\Omega} \rho(x, \delta(y)) \rho(x / y) d x=M[\rho(x, \delta(y)) / y] .
$$

A posteriori mathematical expectation of the RF is called a posteriori risk (AR).

Therefore, the Bayesian solution can be found by minimizing the AR, which is

$$
\tilde{R}(y, \delta) \longrightarrow \min _{\delta}(\mathrm{inf}) .
$$

It should be noted that this statement is correct in the case when $x$-is a discrete random variable.

It should also be noted that

$$
R\left(\rho_{0}, \delta^{*}\right)=M\left[\widetilde{R}\left(y, \delta^{*}\right)\right]=M\left\{M\left[\rho\left(x, \delta^{*}(y)\right) / y\right]\right\}=M\left[\rho\left(x, \delta^{*(y)}\right)\right]
$$

and therefore, the mathematical expectation of the minimal AR gives the Bayes risk.

\subsection{Minimax solutions.}

The Bayesian approach is connected to two limiting assumptions, the second of which is usually the strongest. If a priori distribution of the variable $x$ is not known, the Bayesian approach in the form demonstrated above cannot be applied. In this case, various non-Bayesian methods of the DM are used, under which both assumptions of the Bayesian approach are not made.

One of these methods is the minimax solution method. The decision function $\delta^{*}$ is called the minimax solution if

$$
\sup _{x} r\left(x, \delta^{*}\right) \leq \sup _{x} r(x, \delta)
$$

for all $\delta$. The value of $\sup _{\delta} r\left(x, \delta^{*}\right)$ is called the minimax risk (MR). 
If each of the spaces $x \in \Omega$ i $\delta \in \Delta$ contains only a finite number of elements (finite-dimensional), then obviously there is always the minimax solution $\delta^{*}$, for which $\min _{\delta} \max _{x} r(x, \delta)=\max _{x} r\left(x, \delta^{*}\right)$.

The minimal solution is the best solution in the worst conditions, and that means the solution is guaranteed.

In the general case, finding the minimax solution is a rather difficult task. However, the minimax solution $\delta^{*}$ with some slight limitations (Sosulin, 1978; Volodin, 2010) is the Bayesian solution with regard to a relatively favorable a priori distribution that maximized the Bayes risk, i.e. that value of $\tilde{F}_{0}$, for which

$$
\inf _{\delta} R\left(\widetilde{F}_{0}, \delta\right) \geq \inf _{\delta} R\left(F_{0}, \delta\right)
$$

for all $F_{0}$. In this case, the minimax risk is equal to the Bayes risk:

$$
\inf _{\delta} \sup _{x} r(x, \delta)=\inf _{\delta} R\left(\widetilde{F}_{0}, \delta\right),
$$

and RF $r\left(x, \delta^{*}\right)$ of the minimax solution $\delta^{*}$ does not depend on the values of the variable $x$.

Here, among other things, it can be concluded that if the BR $R\left(F_{0}, \delta^{*}\right)$ for certain a priori distribution $F_{0}$ is independent of $x$ (permanent at $\Omega$ ), then a priori distribution of $F_{0}$ is the least favorable $\left(F_{0}=\tilde{F}_{0}\right)$, whereas the Bayesian solution $\delta^{*}$ - is the minimax solution. This fact helps search for the least favorable a priori distribution (often, it turns out to be "uniform") and for minimax solutions.

\section{Guaranteed solution in the conditions of the mixed information environment.}

The degree of complexity of the system of management and decision-making in «riskology» depends on the level of information certainness, and the quality thereof is higher if the mixed uncertainty is accounted: stochastic, multiple and ambiguous. The generalized model of the studied economic or environmental process can be shown as $F_{0}: U \mathrm{x} W \rightarrow X$, and the models of monitoring of the factors and indicators as:

$$
F\{C 1\}: X \times V_{X} \rightarrow Y, F\{C 2\}: C \times V_{C} \rightarrow \widetilde{C},
$$

where

$I_{c}=\left\{p(w), p\left(v_{x}\right), p\left(v_{c}\right)\right\}$ is the information field of stochastic uncertainty;

$I_{\mu}=\left\{w \in W, v_{x} \in V_{x}, v_{c} \in V_{c}\right\}$ - is the information field of multiple uncertainties;

$I_{M}=\left\{\mu_{X_{0}}, \mu_{V_{0}}, \mu_{G} *\right\}$ is the unclear information field. 
The mixed information uncertainty now can be described in the form of the following sequence: $I_{0}=\left\langle I_{C}, I_{M}, I_{H}\right\rangle$. In this case, the uniform base of data and knowledge of the integrated management system comprises the totality of three bases of all levels of hierarchy: $I=\left\langle B_{0}, B_{1}, B_{2}\right\rangle$.

As the device functions of $\mu_{X_{0}}, \mu_{V_{0}}, \mu_{G^{*}}$, one can use, for instance, the "Gaussian" radial functions.

Therefore, in this case the task of management (decision-making) can be reduced to solution of the following optimal task:

$$
u=\operatorname{Arg} \max M_{w}\left\{\mu_{d}(x, w)\right\}=\operatorname{Arg} \max _{u \in U} M_{w}\left\{\mu_{X_{0}}\left(F_{0}(u, w)\right) \cdot \mu_{V_{0}}(u) \cdot \mu_{G^{*}}(g)\right\}
$$

at $C \in C^{*}$, where $M$ is the symbol of mathematical expectation, and $U=\left\lfloor u, r+\varepsilon_{\text {лnр }}\right\rfloor$ is the decision made by the PD.

\section{Models of penalties for loss and the PD's task.}

Let's assume that $u_{i} \geq 0$ is the volume of production, and $v_{i} \geq 0$ is the volume of expenses on environment conservation measures taken by the $i$-th enterprise, and at the same time it's production-related activities always entail the loss totaling $Y_{i}^{0} \equiv Y_{i}^{0}\left(u_{i}, v_{i}\right) \geq 0$. However, the real amount of loss $Y_{i} \geq Y_{i}^{0}$ is a random value that has its function (density) of distribution of probability. Often, the information on the actual amount of the loss is lacking, and the only available information is that on the density of distribution of probabilities, such as $f\left(Y_{i}, Y_{i}^{0}\left(u_{i}, v_{i}\right), \alpha_{i}\right)$.

Assume that $z_{i}\left(u_{i}\right)$ denotes production expenses for the production volume totaling $u_{i}$, and the target function is the profit of the $i$ - th enterprise, i.e $P_{i} \equiv P_{i}\left(u_{i}, v_{i}, \chi_{i}().\right)$, whereas $\chi_{i}($.$) is the amount of$ penalty (the function of some indicators), which is set by the "Center" depending on the amount of actual losses inflicted on the environment by the $i$ - th enterprise.

Then, the expected profit of the $i$ - th enterprise is the following function:

$$
P_{i}\left(u_{i}, v_{i}, \chi_{i}(.)\right)=p_{i} \cdot u_{i}-z_{i}\left(u_{i}\right)-v_{i}-\int_{Y_{i}} \chi_{i}(\cdot) f\left(Y_{i}, Y_{i}^{0}\left(u_{i}, v_{i}\right), \alpha_{i}\right) d Y_{i},
$$

where $p_{i}$ - is the price of a unit of production of the $i$ - th enterprise.

The totality of solutions for the enterprise is an indefinite number of couples of the following type: 


$$
D=\left\{(u, v): \operatorname{Arg} \max _{\left(u_{i}, v_{i}\right)} P_{i}\left(u_{i}, v_{i}, \chi_{i}(.)\right)\right\}
$$

\section{Decision-making task.}

Managerial decision-making by the "Center" means selection of the system of penalties $\left\{\chi_{i}(\cdot)\right\}$, maximizes the mathematical expectation of the criterion of the "Center", i.e. its utility function, for instance, $M_{y}[\Phi(u, v, Y)]$ in the totality $D$ :

$$
\max _{(u, v) \in D} M_{y}[\Phi(u, v, Y)] \Rightarrow \max _{\left\{x_{i}\right\}} \quad \text { or } \max _{(u, v) \in D} \int_{Y} \Phi\left(u, v, Y_{i}\right) f\left(Y_{i}, Y_{i}^{0}\left(u_{i}, v_{i}\right), \alpha_{i}\right) d Y_{i} \Rightarrow \max _{\left\{x_{i}\right\}} \text {. }
$$

\section{Level of danger and risk.}

Let's use $y_{i}(t)$ - to denote the current level of safety, and $x_{i}(t)$ - the required (desirable) level of safety of the $i$ - th enterprise at the moment of time $t$. It should be noted here that the notion of the "danger level" (DL) and the "risk level" (RL) is dubious, for instance, the increased RL results in the decreased DL and vice versa, i.e. $\mathrm{DL}=1$ - RL.

If $S_{i}$ is the amount of penalty for ensuring the required DL, the profit that is retained by the $i$ - th enterprise can be described as the following function:

$$
P_{i}=p_{i} \cdot u_{i}-P_{i}\left(u_{i}, v_{i}, \chi_{i}(.)\right)=p_{i} \cdot u_{i}-z_{i}\left(u_{i}\right)-v_{i}-S_{i}\left(x_{i}, y_{i}\right) .
$$

where as

$$
S_{i}\left(x_{i}, y_{i}\right)=\left\{\begin{array}{l}
0, \text { если } y_{i} \geq x_{i}, \\
\chi_{i}\left(y_{i}\right), \text { если } y_{i}<x_{i}
\end{array}\right.
$$

For instance, when the set value of risk or danger of $q_{i}$ for the $i$-th enterprise takes into account certain economic mechanism for ensuring safety, the penalty function is $\mathrm{S}_{i}\left(x_{i}, y_{i}\right)=q_{i} \cdot\left(x_{i}-y_{i}\right)$ at $y_{i} \leq x_{i}$, i.e. provided the required DR is not achieved (otherwise it will be fined). Other options of the penalty functions can be found, for instance, in the monograph (Burkov et al, 2008). 


\section{CONCLUSION}

This paper offers the models of the tasks related to decision-making in the conditions of risks, danger, and in the conditions of mixed information environment, models of penalty for damage for harmonization and optimization of the risk and safety of a complex system. The paper continues the author's studies in the sphere of modeling, predicting and managing complex social, environmental, and economic systems for safe, viable, sustainable and harmonious development in the current conditions of risks and crises.

\section{Conflict of interests}

The authors declare no conflict of interest.

\section{References}

Burkov VN, Novikov DA, Shchepkin AV Mechanisms of management of ecological-economic systems./Ed. SN Vasil'eva.-M.: Izdv. Phys.-Mate. Lit., 2008. .-244 p.

Kurmanov N.A., Toksanova A.N. Mukhamedzhanov A.A., Syrlybayeva N.Sh.; M.M., Petrova. Analysis of efficiency of innovation activities in the countries of the Eurasian Economic Union. The Journal of Economic Research \& Business Administration, [S.1.], v. 126, n. 4, p. 35-51, 2018. eISSN 2617-7161. pISSN: 1563-0358. Al-Farabi Kazakh National University, Available at: https://be.kaznu.kz/index.php/math/article/view/2026

Lukjanova, J., Sushchenko, O., Zima, O. (2019). Educated and competent staff as important factor of innovation development of machine-building and metalworking industry in Latvia, ISPCIME-2019. MATEC Web of Conferences, EDP Sciences, vol.297 (06006), 2019, DOI: https://doi.org/10.1051/matecconf/201929706006

Levashova, L. (2011). Marketing wewnętrzny w kontekście motywowania pracowników, w: Świerszcz K. i Nowacki W., Kształtowanie lojalności klientów $w$ teorii $i$ w praktyce. Warszawa: Wydawnictwo Warszawska Wyższa Szkoła Ekonomiczna.

Levashova, L. (2011). Rozwój kariery zawodowej pracowników w aspekcie innowacji, w: Innowacje przedsiębiorstw a satysfakcja klientów $w$ teorii $i w$ praktyce, pod redakcja naukowa Świerszcz K. $i$ Śliwa J. Warszawa: Wydawnictwo Społeczna Wyższa Szkoła Przedsiębiorczosci i Zarządzania w Łodzi.

Nenkov, N., Sushchenko, O., Dyachenko Y. (2017) Role of chief information officer within the system of human resource development in the service organizations (tourism) // Economic Annals-XXI. - Issue 5-6. - Vol. 165. - P. 97-103.

Ramazanov S.K. Innovative technologies of crisis management of economic systems. Monograph, S.K. Ramazanov, G.O. Nadyon, N.I. Crystal, O.P. Stepanenko, L.A. Timashova; Ed. prof. S.K. Ramazanova - Lugansk - Kyiv: View of the SNU them. V. Dahl, 2009. - 584 p.

Ramazanov S.K. Optimization of risk and security for harmonious and sustainable development of complex systems. P. 45-55, Modeling of processes in economics and project management using new information technologies. Monography. / For the community Ed. VO Timofeev, IV Chumachenko - Kharkiv: KNURE, 2015 - 245 p.

Ramazanov, S. Petrova, M. (2020). Development management and forecasting in a green innovative economy based on the integral dynamics model in the conditions of «Industry - 4.0». Access journal, ACCESS Press, 1(1): 9-30, DOI: https://doi.org/10.46656/access.2020.1.1(1)

Ramazanov S.K., Burbelo O.A., Vitlinsky V.V., and others. Risks, security, crises and sustainable development in the economy: methodologies, models, methods of management and decision-making. Monograph / Under the congregation. Ed. prof. S.K. Ramazanova - Lugansk: View of "Nulledzh", 2012. - 948 p.

Ramazanow S.K., Stemplewska L., Analiza, modelowanie oraz prognozowanie stanu i rozwoju kryzysowej sytuacji socjalno-politycznej: pewne rozważania wstępne, Studia i materiały, Zeszyt 8 (lipiec - grudzień), Oficyna wydawnicza Europejskiej Uczelni, Warszawa 2014. p. 78. 
Ramazanov S.K., Stemplewska, L. (2017). Sustainable Development and Integral Model of Socio-Ecological and Economic Management in Crisis, Proceedings of the IV International Scientific and Practical Conference "Mechanisms, Strategies, Models and Technologies of Management of Economic Systems in the Conditions of Integration Processes: Theory, Methodology, Practice", 6-8 October 2017, Khmelnitsky, p.63-64

Sosulin Yu. G. Theory of Detection and Estimation of Stochastic Signals. - M .: Sov. Radio, 1978. - 320 p.

Stemplewska, L. (2011). Wpływ otoczenia ekonomicznego na efektywność systemów motywacyjnych w przedsiębiorstwach. Warszawa: Wydawnictwo Elipsa.

Sushchenko, O. (2016). Creation of innovation clusters as a line of enterprise competitiveness improvement in the field of foreign economic activity, Actual Problems of Economics, 177(3), 191-198

Volodin I.N. Lectures on the theory of statistical conclusions. Uch Positive / I.N. Volodin - Kazan: K (P) FU, 2010. 174 s.

\section{About the authors:}

Sultan RAMAZANOV, Doctor of Technical Sciences, Doctor of Economics, Professor Emeritus of East Ukrainian National University V. Dalia, Honoured Worker of Science and Technology of Ukraine (Ukraine), Academician of academies: MAI, MANEB, AENA, TAU, ANTU. Professor of the Department of Information Systems in Economics, Institute of Information Technology in Economics, Vadym Hetman Kyiv National Economics University, Kyiv, Ukraine. Research interests: nonlinear modeling in socio-economic and environmental systems, intelligent systems and modeling technologies, forecasting of environmental and economic processes and systems, management and decision making.

ORCID ID: https://orcid.org/0000-0002-8847-6200

Ludmila STEMPLEWSKA, PhD of Economics, Professor, Vistula University, Vistula Academy of Finance and Business in Warsaw, Poland. Research interests: innovation, innovation activity, start-up, small and medium enterprises, economic growth, management and decision making.

ORCID ID: https://orcid.org/0000-0002-4465-8918

Copyright (C) 2020 by author(s) and ACCESS Publishing Press This work is licensed under the Creative Commons Attribution International License (CC BY) 